\section{Air quality changes in Mexico City, London and Delhi in response to various levels of lockdown restrictions during the COVID-19 pandemic}

\author{
ELIZABETH VEGA RANGEL ${ }^{1}$, ANIL NAMDEO ${ }^{2}$, \\ LINDSAY BRAMWELL ${ }^{2}$, YOSUNE MIQUELAJAUREGUI ${ }^{1}$, \\ CINTIA RESENDIZ-MARTINEZ ${ }^{3}$, MONICA JAIMES ${ }^{3}$, \\ FRANCISCO LUNA ${ }^{3}$, ANTONIO TERRAZAS-AHUMADA ${ }^{3}$, \\ KAMAL MAJI $^{2}$, JANE A ENTWISTLE ${ }^{2}$, JUAN CARLOS \\ NÚÑEZ ENRÍQUEZ ${ }^{4}$, JUAN MANUEL MEJIA ${ }^{4}$, ANTONIO \\ PORTAS $^{2}$, LOUISE HAYES ${ }^{5}$ AND RICHARD MCNALLY ${ }^{5}$ \\ ${ }^{1}$ National Autonomous University of Mexico (UNAM) \\ ${ }^{2}$ Northumbria University \\ ${ }^{3}$ Secretaría de Medio Ambiente \\ ${ }^{4}$ Instituto Mexicano del Seguro Social (IMSS) \\ ${ }^{5}$ Newcastle University \\ Presenting Author: anil.namdeo@northumbria.ac.uk
}

The impacts of COVID-19 lockdown restrictions have provided a natural experiment into the extent of improvements in air quality possible with reductions in vehicle movements. Mexico City, London and Delhi all share the problem of air quality failing WHO guideline limits; each city with its own unique situation and influencing factors. We have determined and compared the air quality changes across these cities during the COVID-19 lockdown restrictions, to understanding how the findings may support future improvements in their air quality and the associated health of citizens.

We analysed ground level $\mathrm{PM}_{2.5}, \mathrm{NO}_{2}, \mathrm{O}_{3}$ and $\mathrm{CO}$ changes for the period 1st January to 31st August 2020 under different phases of lockdown, with respect to average daily concentrations over the same months for 2017 to 2019. Data was downloaded for 10 monitoring sites in Mexico City (RAMA), 12 locations in London (AURN) and 11 locations across Delhi (CPCB, DPCC). Data analysis was carried out using $\mathrm{R}$ packages Openair; reshape2; dplyr and ggplot. We used linear regressions and ANOVAs to test for the relative effect of lockdown phases and land use type.

We found major reductions in $\mathrm{PM}_{2.5}, \mathrm{NO}_{2}$ and $\mathrm{CO}$ across the three cities for the lockdown phases and increases in $\mathrm{O}_{3}$ in London and Mexico City, but not Delhi. Levels of reductions were commensurate with degree of lockdown. In Mexico City the greatest reduction in measured concentration was in $\mathrm{CO}$ in the initial lockdown phase $(48 \%)$, in London the greatest decrease was for $\mathrm{NO}_{2}$ in the later part of the lockdown (49\%), in Delhi the greatest decrease was in $\mathrm{PM}_{2.5}$ in the initial lockdown phase $(50 \%)$. In general, reduction in pollutant concentrations agreed with reductions in vehicle movements. In the initial lockdown phase vehicle movements reduced by up to $59 \%$ in Mexico City and $63 \%$ in London ${ }^{3}$. The cities demonstrated a range of air quality changes linked to their differing geographical settings and land use types (e.g. traffic, background, industrial). Local meteorology and pollution events, such as forest fires, also impacted the results.

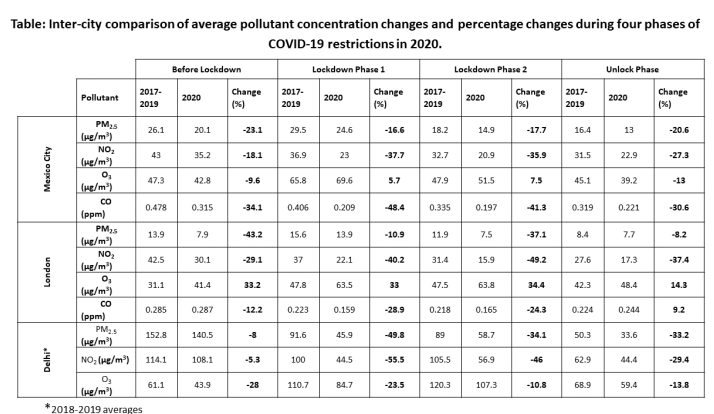

